\title{
Correction: Effect of an Inpatient Rehabilitation Program for Recovery of Deconditioning in Hematologic Cancer Patients After Chemotherapy
}

\author{
Seungwoo Cha, $\mathrm{MD}^{1}$, Inho Kim, MD, $\mathrm{PhD}^{2}$, Shi-Uk Lee, MD, $\mathrm{PhD}^{3}$, Kwan Sik Seo, MD, $\mathrm{PhD}^{1}$
}

\begin{abstract}
${ }^{1}$ Department of Rehabilitation Medicine, Seoul National University Hospital, Seoul National University College of Medicine, Seoul; ${ }^{2}$ Division of Hematology, Department of Internal Medicine, Seoul National University Hospital, Seoul National University College of Medicine, Seoul; ${ }^{3}$ Department of Rehabilitation Medicine, SMG-SNU Boramae Medical Center, Seoul, Korea
\end{abstract}

http://doi.org/10.5535/arm.2018.42.6.838

Ann Rehabil Med 2018;42(6):838-845

After publication of the article, we found two errors of funding acknowledgment and IRB number. The correct details for acknowledgment of funding is:

This work was supported by the National Research Foundation of Korea (NRF) grant funded by the Korea government (MSIT) (No. 2018R1A2B6001296).

The revised IRB number is shown below.

The study was approved by the Institutional Review Board of Seoul National University Hospital (No. 1701-113-826).

Corresponding author: Kwan Sik Seo

Department of Rehabilitation Medicine, Seoul National University Hospital, Seoul National University College of Medicine, 101 Daehak-ro, Jongno-gu, Seoul 03080, Korea. Tel: +82-2-2072-0608, Fax: +82-2-743-7473, E-mail: snurm@daum.net

(c) This is an open-access article distributed under the terms of the Creative Commons Attribution Non-Commercial License (http://creativecommons.org/ licenses/by-nc/4.0) which permits unrestricted noncommercial use, distribution, and reproduction in any medium, provided the original work is properly cited. Copyright $\odot 2019$ by Korean Academy of Rehabilitation Medicine 